\title{
Postgraduate conception of research methodology: implications for learning and teaching
} \begin{abstract}
This qualitative inquiry investigates postgraduate students' conceptions of research methodology and how it contributes to their learning. It explores factors likely to motivate student choice of research methodology and challenges in understanding research methods. The research was carried out at research-intensive universities in New Zealand and in Malaysia with similar postgraduate programmes. Participants were enrolled in Masters and Ph.D. programmes. Findings revealed that participants share a recognition that research methodology is a significant body of knowledge in postgraduate education. However, there were noticeable differences in perspectives regarding what constitutes research methodology and whether or not it should be conceived as a discipline. To some participants, learning research methodology is less of a discipline but rather an acquisition of a set of isolated facts and skills without necessarily acquiring a deeper understanding of research. Furthermore, postgraduate students choose research methodology based on a number of factors such as familiarity with a method, methodological orientation of the primary supervisor, the domain of study, and the nature of research problems pursued. Participants reported that the key challenges they face in understanding research methodology include framing research questions, understanding the theory or literature and its role in shaping research outcomes, and difficulties in performing data analysis.
\end{abstract}

Keyword: Research methodology; Qualitative research; Conceptions of research; Postgraduate 